\title{
Adsorption of glyphosate onto activated carbon derived from waste newspaper
}

\begin{abstract}
This paper investigates the ability of activated carbon derived from waste newspaper (WNAC) to remove pesticide glyphosate from aqueous solution. The influence of initial $\mathrm{pH}$ was first studied. It was found that the WNAC presented the highest uptake capacity at $\mathrm{pH}$ 2.5. Adsorption isotherm models such as Langmuir, Freundlich and Redlich-Peterson were used to describe the adsorption of glyphosate by WNAC. The results show that the Langmuir adsorption isotherm model best fits the experimental data. The maximum adsorption capacity of WNAC is found to be $48.4 \mathrm{mg} / \mathrm{g}$.
\end{abstract}

Keyword: Pesticide; Glyphosate; Adsorption; Waste newspaper activated carbon 